\title{
PREDICTING THE GEOGRAPHY OF SPECIES' INVASIONS VIA ECOLOGICAL NICHE MODELING
}

\author{
A. Townsend Peterson \\ Natural History Museum and Biodiversity Research Center, University of Kansas \\ Lawrence, Kansas 66045 USA
}

E-MAIL:TOWN@KU.EDU

KEYWORDS

invasive species, ecological niche models, geographic information systems, predictive modeling, niche evolution

\section{ABSTRACT}

Species' invasions have long been regarded as enormously complex processes, so complex as to defy predictivity. Phases of this process, however, are emerging as highly predictable: the potential geographic course of an invasion can be anticipated with high precision based on the ecological niche characteristics of a species in its native geographic distributional area. This predictivity depends on the premise that ecological niches constitute long-term stable constraints on the potential geographic distributions of species, for which a sizeable body of evidence is accumulating. Hence, although the entire invasion process is indeed complex, the geographic course that invasions are able to take can be anticipated with considerable confidence.

NVASIVE SPECIES have become an issue

of great concern in fields as diverse as biology, agriculture, transportation, and economics (Carlton 1996; Kareiva 1996; Williamson 1996, 1999; Enserink 1999; Higgins et al. 1999; NAS 2002). The basic point is that with ever-increasing scales of human movement, species are finding ever-increasing opportunities to move as well, resulting in many introductions of species to novel landscapes (NAS 2002). Although many colonizations fail (Williamson and Fitter 1996), for reasons of demography or of chance, this increased opportunity for colonization certainly plays a major role in increasing numbers of successful invasions.

Several reviews of the natural history and ecology of invasive species have been conducted in the hope of identifying factors key in determining the success of invasions that could serve as the basis for a predictive understanding of which species represent potential invaders (Honig et al. 1992; Perrins et al. 1992; Scott and Panetta 1993; Lonsdale 1994; Carlton 1996; Rejmánek and Richardson 1996; Williamson 1996, 1999; Reichard and Hamilton 1997; Ricciardi and Rasmussen 1998; Enserink 1999; NAS 2002). Unfortunately, the list of such identified key factors is short, consisting principally of characters associated with weedy habit and prior history of successful invasion. More than anything, with a few exceptions (Rejmánek and Richardson 1996), the conclusion has been that

The Quarterly Review of Biology, December 2003, Vol. 78, No. 4

Copyright (C) 2003 by The University of Chicago. All rights reserved.

0033-5770/2003/7804-0002\$15.00 
few or no factors allow consistent prediction a priori of success or failure of invasions. As a result, efforts to combat species' invasions have been largely reactive in nature: a new invader arrives, and a plan must then be developed to combat it.

A distinct approach toward predicting the behavior of invasions, however, can be referred to as "climate-matching" (NAS 2002). This approach is based on the concept of ecological niches as a constraint on the distributional potential of species (Grinnell 1917, 1924), and involves a logical extension of the basic niche concept-that species will be able to establish populations only in areas that match the set of ecological conditions to which they are limited on native distributional areas. This approach has seen application to a broad diversity of species' invasions (Panetta and Dodd 1987; Podger et al. 1990; Richardson and McMahon 1992; Sindel and Michael 1992; Martin 1996; Skov 2000; Hoffmann 2001; Martin 2001; Welk et al. 2002), including the development of convenient, user-friendly software (Sutherst et al. 1999).

More recent applications (Peterson and Vieglais 2001) have developed climate matching more fully under the rubric of ecological niche modeling (Peterson et al. 2002c). In this sense, the ecological niche of a speciesthe conjunction of environmental conditions within which a species can maintain populations without immigration (MacArthur 1972) — is modeled by a variety of approaches based on occurrence patterns within the species's native distribution. This model is then projected to other regions to identify areas potentially habitable by nonnative populations of the species (Figure 1).

This body of work, however, although producing predictions generally considered to be highly statistically significant (NAS 2002), has not seen broad acceptance. Indeed, a recent review could say only that the approach "deserves support and further evaluation" (NAS 2002). I assert that this approach, when properly understood as to where it "fits in" in modeling the invasion process, holds excellent predictive ability, and has much to offer to the field. This assertion is the basis of the present review.

\section{Niches as Constraints on Distribution}

THEORY

Joseph Grinnell was the first investigator to propose a concept of an ecological niche (Grinnell 1917, 1924). The Grinnellian niche focused on the range of ecological conditions within which a species can maintain populations, and therefore by nature was geographic in focus. Later investigators focused niche concepts increasingly on the role of a species in an ecological community (Elton 1927; Hutchinson 1957); the two foci were integrated and made more quantitative by MacArthur (1972). In the Grinnellian and MacArthurian views, the ecological niche is the quantity that limits geographic distributions of species.

A broad suite of recent theoretical treatments (Brown and Pavlovic 1992; Holt and Gaines 1992; Kawecki and Stearns 1993; Kawecki 1995; Holt 1996a, 1996b; Holt and Gomulkiewicz 1996) clarifies the relationship between ecological niches, geographic distributions, and evolutionary dynamics. Under this view, ecological niches delineate the set of conditions under which species can maintain populations in the long term without an in-migration of individuals. Individuals inhabiting conditions outside the niche do not reproduce (or do not replace themselves), and hence contribute little to the long-term evolutionary dynamics of the species. Individuals inhabiting conditions within the niche are generally able to replace themselves, and thus contribute genes to the next generation. Hence, these theoretical treatments suggest that, in general, long-term natural selection pressures will maintain the ecological niche without substantial modification, and niche characteristics will be conserved over evolutionary time periods. As will be discussed later in this paper, this theoretical expectation now has considerable empirical support.

\section{PRACTICE}

In this review, I focus on techniques for ecological niche modeling that relate point occurrence data to geographic information about the ecological characteristics of a land- 


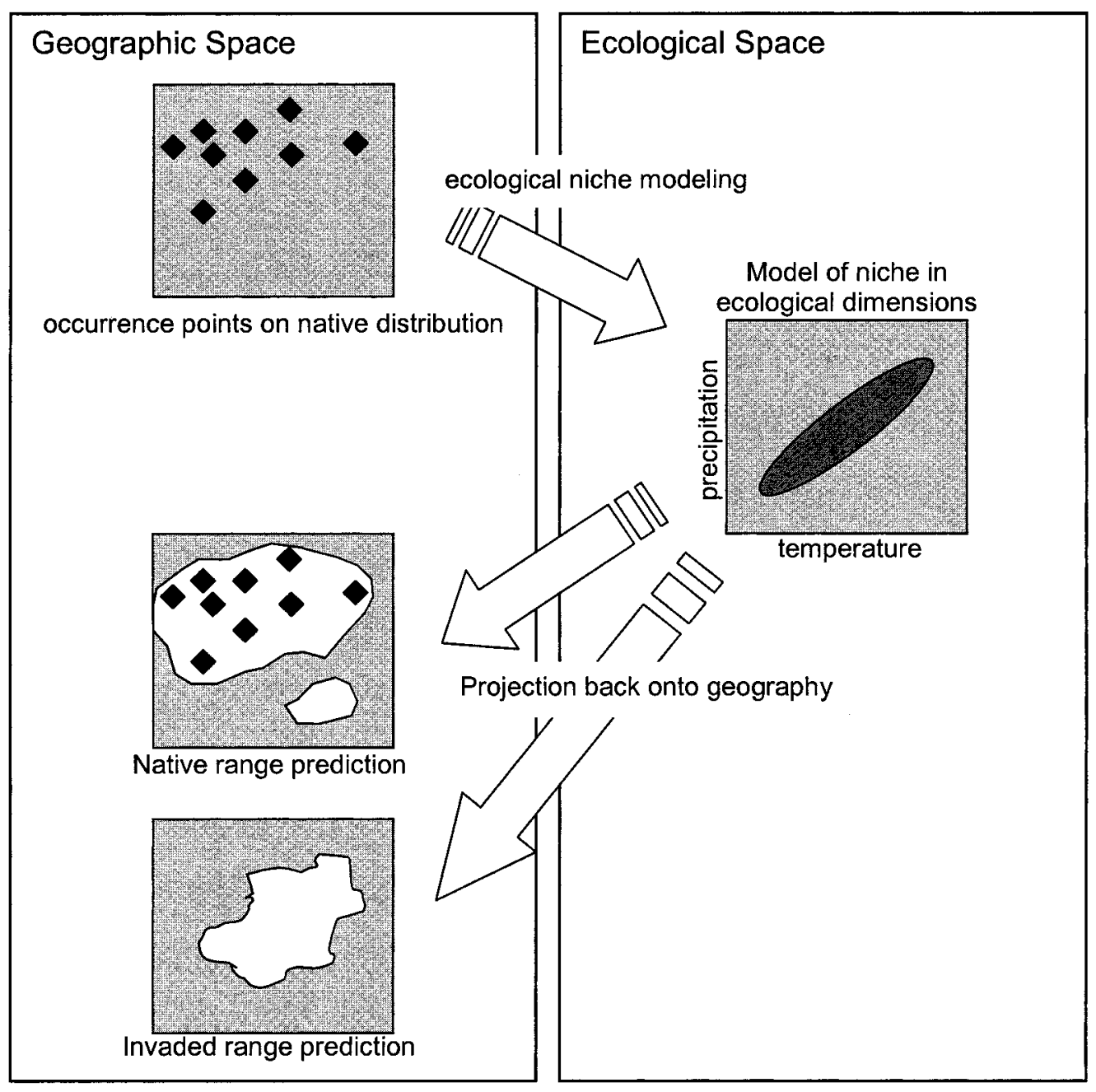

Figure 1. Diagrammatic Representation of Ecological Niche Models that Predict the Geographic Course of Species' Invasions

The figure shows the process of characterizing the distribution of a species in geographic space, modeling the ecological niche in ecological space, and projection back into geographic space to predict distributions both on the native geographic distribution and the invaded geographic distribution.

scape to produce a hypothesis about which ecological features are within a species's niche and which are not. This ability to use occurrence data exclusively permits the application of these techniques to almost any species, and not only to well-known or well-studied species. The ecological niche model can then be projected onto landscapes to identify geographic regions that present ecological conditions inside and outside of the species's niche, producing a hypothesis of a potential geographic distribution for the species. It is critical to distinguish this two-step approach-modeling the niche in ecological space and then projecting the model onto a landscape in geographic space-from other, simpler ("onestep") approaches that do not distinguish between ecological and geographic spaces (Figure 1) (Peterson et al. 2002c).

Many analytical tools have been used to develop such models of ecological niches. Among the simplest and most straightforward 
is BIOCLIM (Nix 1986), which develops a niche model by intersecting the ranges (slightly trimmed) inhabited by the species along each environmental axis (e.g., 1000$1500 \mathrm{~m}$ elevation by $100-200 \mathrm{~mm}$ of rainfall by $20-22^{\circ} \mathrm{C}$ annual mean temperature by etc.). An alternative approach has been that of logistic multiple regression and its more generalized forms, which provides a complementary approach based on a distinct means of inference (Austin et al. 1990). Still other investigators have employed distance-based algorithms, neural networks, and regressiontree analyses, among other approaches (Malanson et al. 1992; Carpenter et al. 1993). Comparisons of relative predictive ability among approaches have nevertheless been relatively few (Fielding and Bell 1997; Manel et al. 1999).

The approaches listed above, however, are mostly deterministic in nature, and focus on a search for a single decision rule, or a small set of decision rules that govern species' distributions. The reality of species' ranges, however, is that many factors affect them, and indeed that different decision rules may govern distributional limits in different sectors of a species's distribution. For example, in the North Temperate Zone, northern distributional limits may frequently depend on freeze frequencies or snow cover, whereas southern distributional limits may depend on temperature maxima or humidity (Grinnell 1917, 1924). Hence, more complex, multiple-criterion approaches are desirable; I focus in particular on a heterogeneous-rule machine-learning approach that has proven particularly useful.

\section{GARP AND GENETIC ALGORITHMS}

The Genetic Algorithm for Rule-set Prediction (GARP) includes several inferential tools in an iterative, artificial-intelligence-based approach (Stockwell and Noble 1992; Stockwell 1999; Stockwell and Peters 1999). Occurrence points are resampled randomly in even proportions to create training and test data sets (1250 points in each set). GARP works in an iterative process of rule selection, evaluation, testing, and incorporation or rejection. First, an inferential tool is chosen from a set of possibilities (e.g., logistic regression, bioclimatic rules), the tool is applied to the training data, and a rule is developed. Rules are evolved by a number of means (e.g., truncation, point changes, crossing over among rules) to maximize predictivity. Predictive accuracy is then evaluated based on the test presence data and on a set of "pseudoabsence" points (points sampled randomly from among points across the entire study region where the species has not yet been detected). The change in predictive accuracy from one iteration to the next is used to evaluate whether or not a particular rule should be incorporated into the model, and the algorithm runs either 1000 iterations or until convergence.

GARP models provide an efficient means of modeling species' ecological niches, and for projecting these models onto geography in the form of maps, which are testable hypotheses of distributional potential. Numerous such tests (Peterson and Cohoon 1999; Peterson et al. 1999; Peterson 2001; Anderson et al. 2002; Feria and Peterson 2002; Peterson et al. 2002a, 2002c; Stockwell and Peterson 2002a, 2002b) have confirmed the predictive nature of these models. Hence, GARP-modeled ecological niches indeed delineate the habitable environmental conditions for a species, and can be used to predict independent test-occurrence data sets with precision.

\section{Distributions Versus Niches}

The niche of a species is formed, by definition, by the ecological conditions that limit the species's distributional potential. However, several additional factors serve to limit a species's distribution to a yet-smaller area, a subset of that potential space. In particular, at least four historical effects (although these effects are in some senses also "ecological") can further restrict a species's distribution:

Limited dispersal-Limited dispersal abilities keep a species from encountering otherwise suitable distributional areas, particularly when these areas are disjunct from the species's present distributional areas (Root 1998; Breininger 1999; Anderson et al. 2002). 
Speciation-Allopatric speciation produces sister species in suitable distributional areas previously inhabited by the ancestral species (Peterson et al. 1999).

Extinction-Populations of the species may previously have existed in an area, but have gone extinct perhaps for demographic reasons, leaving an uninhabited suitable distributional area (Burkey 1995).

Competition-Interspecific competition, to the extent that it may act to limit a species's geographic distribution (MacArthur 1972), can produce absences of species from suitable distributional areas (Anderson et al. 2002).

Any of these phenomena (and others) can lead to the existence of uninhabited suitable distributional areas.

More generally, two patterns are clear: (1) for reasons such as those listed above, the spatial extent of a species's ecological niche is invariably greater than the extent of its actual geographic range; and (2) uninhabited suitable areas are concentrated in disjunct regions. This pattern is expected based on historical causation of some aspects of range limits, and has been confirmed based on inspection of modeled distributions for literally hundreds of species in numerous geographic situations. In terms relevant to the question of predictability of species' invasions, habitable areas almost always exist outside of a species's present geographic distribution.

\section{LONG-Term Stability of Ecological NICHES}

The stability of ecological niches-and consequent predictivity of distributional possibilities-within single evolutionary lineages is little explored, largely owing to the scarcity of well-documented data sets relevant to the question. Nevertheless, the reasoning developed above toward predictivity of species' invasions "works" if and only if phylogenetic inertia exists in ecological niches. That is, if niches are wildly plastic, their utility in predicting the course of invasions would be limited. Hence, tests of the evolutionary conservatism of eco- logical niches become particularly interesting. I will discuss herein three types of such tests: (1) longitudinal tests of the predictability of species' distributions across the Pleistoceneto-Recent transition (about 18,000 years); (2) tests comparing ecological niches of sister species pairs (about 100,000 years); and (3) tests across entire clades (perhaps 100,000 to $1,000,000$ years) .

\section{LONGITUDINAL TESTS}

As a first exploration, ecological niches of mammalian species that survived the Pleistocene-to-Recent transition were modeled to test conservatism between the Last Glacial Maximum (18,000 yr BP) and the present (Martínez-Meyer 2002). The results of this analysis, although preliminary in nature owing to limitations imposed by availability of relevant climatic and species' occurrence data, showed a surprising degree of predictivity of species' distributions through the drastic climate changes at the end of the Pleistocene. In all, for Pleistocene occurrence records predicting present distributions, 17 of 23 tests (species) were statistically significant, and for present occurrence records predicting Pleistocene distributions, 12 of 23 tests were statistically significant. The difference between the two reciprocal tests appears to stem from the disparate samples available for testing model quality-Pleistocene samples appear adequate for building models, but not for carrying out adequate statistical tests of model quality. Considering these aspects of statistical power, model performance in predicting across time periods is even better than at first appearance. In general, it is clear that these species have predictably followed a consistent set of climatic conditions over a period of drastic climate change.

\section{SISTER SPECIES COMPARISONS}

Deeper inspection of the conservative nature of species' ecological niches is provided by comparing ecological characteristics of sister species pairs. Here, conservatism is tested over longer periods of time (around 100,000 years) via reciprocal comparisons of 
sister species pairs (e.g., ecological characteristics of species A predict the distribution of species $B$, and vice versa). Species pairs that exhibit this interpredictivity would have exhibited conservatism in ecological niche characteristics over twice the period of time since speciation.

A first broad test of ecological niche conservatism using this approach demonstrated essentially universal reciprocal predictivity between 37 sister species pairs in southern Mexico (Peterson et al. 1999). Similar comparisons between confamilial species pairs had essentially no reciprocal predictivity, indicating that ecological niche characteristics were conserved over short to moderate periods of evolutionary time. Other previous comparisons (Huntley et al. 1989; Ricklefs and Latham 1992) also indicated excellent interpredictivity among species pairs. Hence, based on this suite of tests, species' ecological niches appear generally stable over time intervals involved in the speciation process.

\section{CLADE COMPARISONS}

Finally, several studies have traced ecological niche characteristics back through evolutionary time based on phylogenetic hypotheses (Kambhampati et al. 2002). Here, comparisons extend from sister species pairs back over much longer time periods. Accordingly, levels of ecological niche conservatism are more variable in these studies (MartínezMeyer 2002).

Enrique Martínez-Meyer (2002) carried out the most detailed such analyses to date. Surveying five recently speciated clades (one lizard, two birds, and two mammals), he found that: (1) niche conservatism was not universal from root to tips of the clades studied; (2) ecological similarities in the deeper parts of the clades were better explained by spatial geographic autocorrelations than by close phylogenetic relationship; and (3) phylogenetically closely related species were indeed generally reciprocally predictive. The overall result suggests that species' ecological niches are stable over moderate periods of evolutionary time, but that changes begin to be observed over longer periods of time.

\section{Predicting the Geographic Potential OF INVASIONS}

The reasoning developed above supports the idea that species' ecological niches indeed represent long-term stable constraints on geographic distributional potential. Models developed using ecological niche modeling techniques provide an adequate, predictive basis for understanding species' ecological niches. Distributional potential of species in regions other than their native ranges can thus be predicted via detection of conditions that fit the species' ecological niche in those regions. This general approach was prototyped based on tests with avian invasions (Peterson and Vieglais 2001), and has now been tested further based on diverse examples, including plants, insects, molluscs, and vertebrates, terrestrial and aquatic systems, apart from the broad literature that presents examples in which climate-matching approaches in general provided good predictivity of geographic invasive potential (Panetta and Dodd 1987; Podger et al. 1990; Richardson and McMahon 1992; Sindel and Michael 1992; Martin 1996; Skov 2000; Hoffmann 2001; Martin 2001; Welk et al. 2002). A worked example follows (Peterson et al. 2003).

\section{HYDRILLA IN NORTH AMERICA}

The aquatic plant Hydrilla verticillata is an aggressive invader in North America, from a native distribution in Southeast Asia and probably the Australo-Pacific region. It causes substantial economic hardship via interference with transportation, recreation, and other human activities in freshwater habitats, displaces native aquatic plant communities, and generally adversely impacts freshwater habitats (Langeland 1996).

Thirty distributional points were available from the native distributional area of this species, which were used to develop an ecological niche model in GARP. The prediction for the native distribution (Figure 2, top) was highly statistically significant, based on repeated random equal splits of available occurrence data into training and test data sets. Indeed, the probability of obtaining such coincidence between random predictions and the test points never exceeded 0.0001 . 


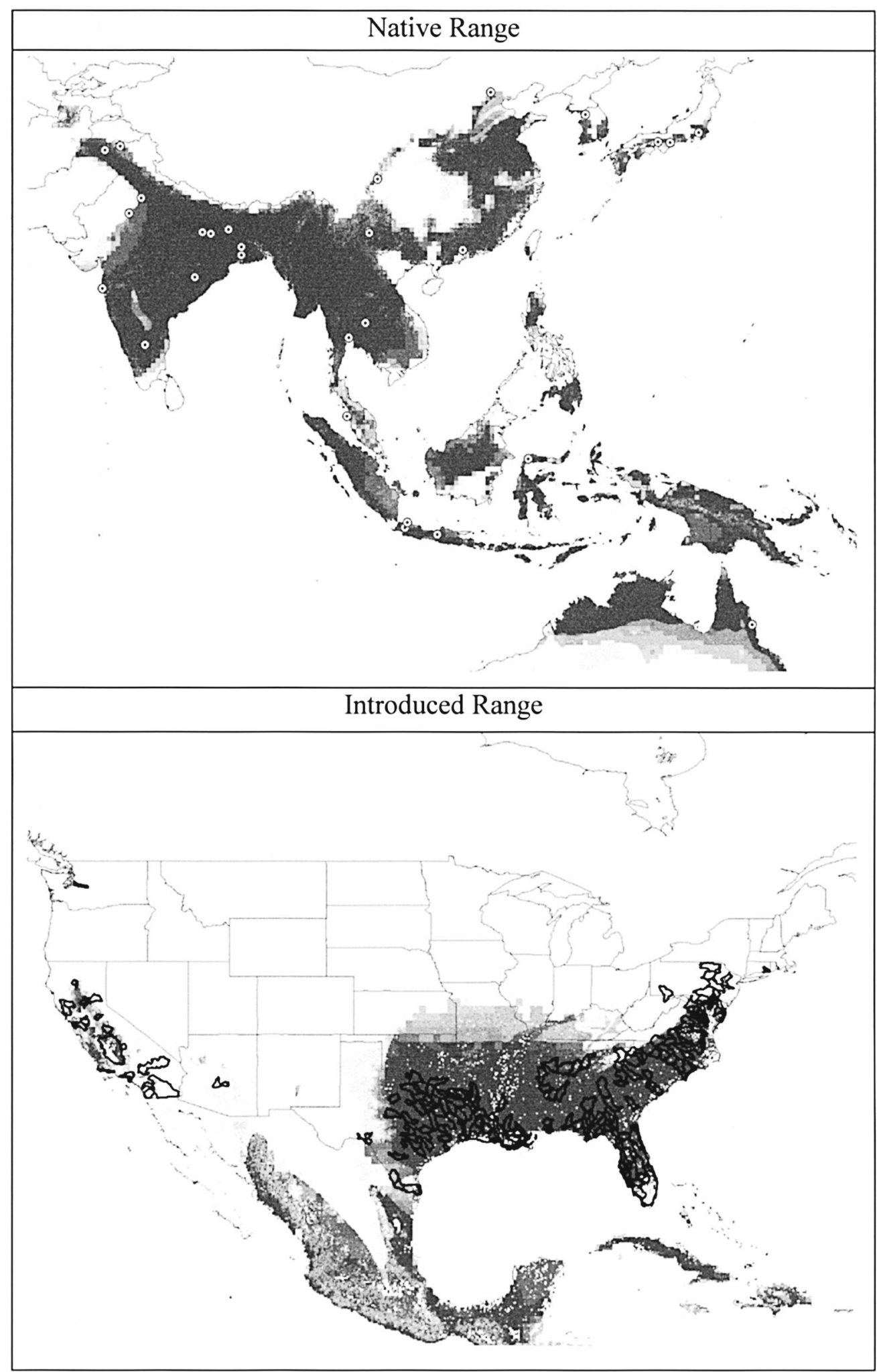

Figure 2.

Ecological niche model for Hydrilla verticillata, projected onto its native distributional area in Southeast Asia and the Australo-Pacific region (top), and its invaded distributional area in North America (bottom). Darker shading of areas indicates greater confidence in prediction of presence. Watersheds actually invaded by the species are shown in black. 
Projecting the Hydrilla ecological niche model onto North America predicts potential distributional areas across the southeastern portion of the continent (Figure 2, bottom). A randomization test was used to assess coincidence between the model's predictions and distributions of watersheds from which the species is known as an invader; a distribution of randomized resamplings of equivalent numbers of watersheds was used to distinguish background coincidence expected under a null model. Coincidence of prediction and known watershed occurrences was highly significant: coincidence of random sets of watersheds with model predictions ranged from 90 to 130 watersheds, whereas observed coincidence was 247 watersheds (Peterson et al. 2003). Hence, the geographic course of the invasion of this species in North America was predicted with considerable confidence, based on its ecological characteristics on its native geographic distribution.

\section{SUMMARY OF TESTS OF PREDICTIVITY}

Between the previous "climate-matching" studies and the more recent work carried out under the rubric of ecological niche modeling, this general approach has now been applied to a large number of test cases. Species that have been examined are diverse, including plants and animals, freshwater and terrestrial species, and vertebrates and invertebrates. Almost invariably, predictivity of the geographic course of species' invasions has been excellent (Panetta and Dodd 1987; Podger et al. 1990; Richardson and McMahon 1992; Sindel and Michael 1992; Martin 1996; Skov 2000; Hoffmann 2001; Martin 2001; Peterson and Vieglais 2001; Welk et al. 2002; Papes and Peterson 2003; Peterson et al. 2003; Peterson and Robins 2003). This significant predictivity is the "proof in the pudding"-species follow the ecological rules that can be reconstructed based on their native distributional ecologies wherever they are in the world.

\section{Limitations}

In general, the methods described in this review show great promise for anticipating the potential geography of species' invasions; however, some limitations should be mentioned. First, the analyses used in the above discussions are computation intensive, with a typical analysis (e.g., 40 to 50 base environmental coverages, 1000 to 10,000 iterations, $0.01 \%$ convergence limit) often taking 5 to 10 minutes of CPU time at $1 \mathrm{GHz}$ processing speed; an "ideal" analysis $(100+$ base environmental coverages, 10,000 to 100,000 iterations, $0.001 \%$ convergence limit) can absorb hours of computing time per model. As current best-practice procedures involve the development of hundreds or thousands of models to produce a suitability surface for a particular species (Anderson et al. 2003), considerable computational capacity is necessary for the development of models even for a single species.

The genetic algorithm used to develop ecological niche models (Stockwell and Noble 1992; Stockwell 1999; Stockwell and Peters 1999) was originally implemented as a UNIXaccessible application, which was later made Web accessible. This implementation, however, was difficult to use efficiently when multiple models were required. The program has now been implemented in a PC environment, with a user interface that permits efficient development of large numbers of models (e.g., 100 species $\times 100$ replications each), and is available for public download (http:/ / www.lifemapper.org/desktopgarp). This functionality for processing large numbers of models opens the temptation of implementing risk assessments across entire floras or faunas, or other such computing-intensive analyses. Such applications will, in large part, however, have to await improvements in computer processing speed.

Availability of point occurrence data, however, remains a more serious limitation; such data are presently available for only a limited swath of species. Broadscale biodiversity information networks that link natural history museum specimen databases are only now being assembled-e.g., The Species Analyst (http://speciesanalyst.net), REMIB (http:// www.conabio.gob.mx). Data are otherwise available from: (1) museums queried for specimen holdings individually; (2) particular data sets (e.g., "Bees of Madagascar," or somesuch); (3) monographic treatments; (4) floras or 
other biotic inventories; and (5) observational datasets. As an example of the dimensions of this limitation, in recent analyses of four North American invasive plant species (Peterson et al. 2003), more than $95 \%$ of time in the study was spent assembling occurrence information from herbarium records and other sources, and only a small portion of the time was dedicated to actual model development. All of the above sources of occurrence information still present the challenge of georeferencing, making for an additional time bottleneck, although some automated approaches are now under development (http://www.biogeomancer.org).

The principal limitation on the predictability of the geography of species' invasions might be that of evolutionary change in ecological niche parameters. Although the general rule appears to be one of conservatism in ecological niches (Huntley et al. 1989; Peterson et al. 1999; Peterson and Vieglais 2001; Anderson et al. 2002), as expected based on recent theoretical work as well (Brown and Pavlovic 1992; Holt and Gaines 1992; Kawecki and Stearns 1993; Kawecki 1995; Holt 1996a, 1996b; Holt and Gomulkiewicz 1996), ecological niches obviously do evolve. In fact, the conservatism so often cited in this review breaks down at some point between sister species pairs and confamilial species, with predictability of confamilial distributions being nil (Peterson et al. 1999; Martínez-Meyer 2002). The unknown limitations to these methodologies are thus the true exceptions to predictivity of invasive distributions based on native-distribution ecological niches, when evolutionary change in niche parameters occurs over short time periods. For example, a recent review (NAS 2002) cited the example of Sorghum halepense as an exception to predictivity based on climate considerations (Warwick et al. 1984), although this particular example has not, to my knowledge, been analyzed quantitatively to demonstrate failure of the methods. Still, several other species have over the past three years been presented to me as situations in which the ecological niche modeling approach would fail, and each has, in the end, seen excellent predictivity. The situations and conditions under which these evo- lutionary shifts can and do occur remains a fruitful-and largely unexplored-field of inquiry with much to offer for future investigation (Etterson and Shaw 2001).

\section{Frontiers and Possible Applications \\ STRATEGIZING FOR COMBATING INVASIONS}

The finding of predictivity of the potential geography of species' invasions permits development of alternative scenarios of successful versus unsuccessful invasions. These scenarios in turn can be used to anticipate critical routes, arrival sites, and initiation points for successful invasions (NAS 2002). Such information would constitute an important step toward an effective strategy against a particular invasion.

As an example of this capability, a previous analysis (Peterson and Vieglais 2001) evaluated the invasive potential of the Asian longhorned beetle (Anoplophora glabripennis) in North America. This wood-boring species had already appeared in packing material in warehouses in 42 cities across the continent, and had managed to colonize trees in the vicinities of Chicago and New York City (Figure 3). These populations are now the subject of intensive control efforts, and the opportunity for a broad invasion is clear.

Ecological niche modeling identified a region of suitable climatic conditions extending across the southern fringe of the Great Lakes (Figure 3). Melding the ecological niche model results with models of spread and diffusion of the species across the variable surface of climate suitability (Hargrove et al. 2000) revealed that regardless of where initiation of invasions was most successful invasions began in that region. Although the models predicted reasonably suitable habitat across much of the eastern United States (which probably also merits supervision), the area south of the Great Lakes appears to be critical to successful invasion by this species. More interestingly, the Pacific coast, where the bulk of Asian shipping arrives, appears relatively inhospitable for the species. A similar example recently developed has examined the potential areas for invasion of the Pacific Northwest by Strix varia, an owl native to east- 


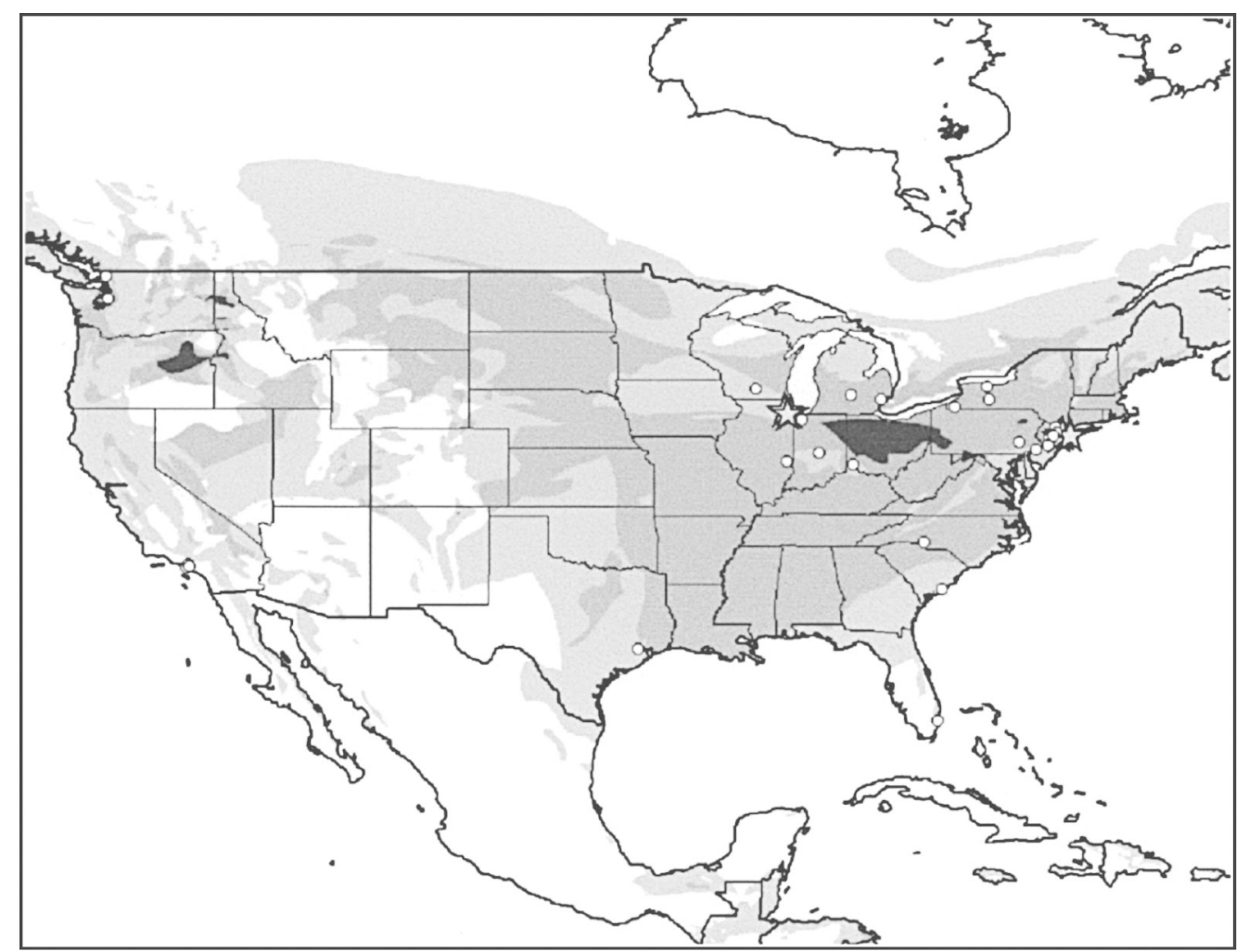

Figure 3.

Projections of Asian longhorned beetle (Anoplophora glabripennis) ecological niche models (developed on the species's native distribution in Asia) onto a Mercator projection of North America. Darker shading indicates greater confidence in prediction of presence. Warehouse occurrences are indicated as white circles, and successful invasions of trees are indicated as stars.

ern North America (Peterson and Robins 2003).

Hence, ecological niche modeling approaches can be used to evaluate invasive potential of a nonnative species, and in particular to identify key geographic areas, corridors, or areas of broad expansion. This capability, which has seen ample empirical support from both the climate-matching and ecological niche modeling experiences, can greatly inform combat and control efforts for a particular species once it has been detected as present in a nonnative distributional area.

\section{ANTICIPATING INVASIONS BEFORE THEY OCCUR}

The predictive nature of ecological niche models regarding potential geographic distri- butions of invasive species can be taken beyond the simple idea of assessing invasive potential retroactively, as in the examples reviewed above. That is, invasive potential can be identified and assessed before an invasion takes place, as has been implemented amply in state and national invasive species monitoring schemes in Australia (Thorp and Lynch 2000). This capacity permits evaluation of invasion risk even before a species could be classed as invasive.

An example of this proactive capacity was developed in an earlier publication (Peterson and Vieglais 2001). Although the publication focused principally on assessing the invasive potential of a species already in the process of invading in North America (Asian longhorned beetle), models were developed also 
for a congener not then known to be invasive in North America (citrus longhorned beetle, Anoplophora malasiaca). While the manuscript was in review, A. malasiaca indeed appeared in North America as an exotic (http:// www.gacaps.org/pests/otherlb.html).

Although the invaders were eradicated, their invasive potential had been predicted in the earlier models, and their geographic potential remains to be tested via future colonization opportunities for the species.

\section{PREDICTING INVASIONS ACROSS SCENARIOS OF CHANGE}

The predictive nature of species' geographic distributions from their ecological niches has been extended over scenarios of invasion (Peterson and Vieglais 2001), and separately over scenarios of climate change (Peterson et al. 2001; Martínez-Meyer 2002; Peterson et al. 2002b). The reality of present environments, however, is that climates are changing rapidly (Karl et al. 1996; O’Brien and Liverman 1996; Magnuson 2000) and biodiversity is already showing the effects of these changes (Parmesan 1996; Visser et al. 1998; Parmesan et al. 1999; Chapin et al. 2000; Inouye et al. 2000; Kovats et al. 2001; Walther et al. 2002); hence, future invasions will occur in the context of changing climates, and consequently changing opportunities for invasion across geography. Unification of predictive analyses across these two phenomena (invasions and climate change) is completely feasible, yielding predictions of opportunities for invasions in the face of global climate change. Integrating projections of invasions with other scenarios of change, such as human-induced changes in land use and land cover, is equally feasible. A limitation of these explorations, however, is the lack of appropriate baseline data sets to permit quantitative statistical validation of predictivity across multiple scenarios of change.

\section{BIOTA-WIDE RISK ASSESSMENTS}

The demonstration of broad predictivity of species' invasive potential opens the door to the possibility of biota-wide risk assessments of invasive potential, as has been partially implemented for Australian banksias possibly invading the South African fynbos biome (Honig et al. 1992). Although limited by the availability of occurrence information for entire biotas for source areas, this step can potentially inform efforts to avoid further problems with invasives enormously.

\section{Discussion}

Species' invasions represent the combination of four factors: (1) colonization opportunity to permit species to reach new areas; (2) avoidance of demographic problems of small population size early in the establishment of invasive populations; (3) ecological appropriateness of the new landscape; and (4) contagion and extension across that landscape (Hobbs and Humphries 1995; NAS 2002). The ecological niche modeling approach (Peterson and Vieglais 2001) focuses solely on the third issue, even though this subject was almost completely omitted from a recent symposium and review of predictivity of invasion processes (Kareiva 1996). Colonization opportunities depend on sets of factors that include human economic activity and transportation patterns, wind and ocean currents, and other potential vectors of long-distance movement. Demographic challenges depend on a series of well-known stochastic factors associated with small population size that can extinguish a small population in spite of the presence of appropriate conditions and even in spite of positive deterministic population growth. Contagion and extension of species' distributions across the new landscape in turn depend on dispersal ability, movements of environmental media or other species that may help to disperse the invader, and landscape continuity or fragmentation.

In this sense, the ecological niche models assess only one step in a complex phenomenon: introduction and establishment of nonnative populations, appropriateness of the landscape for the invader, and spread across the landscape. A recent review (NAS 2002) pointed out that the first stage is generally much better understood than subsequent ones. To predict the actual course of an invasion-is the species here or here and not 
there-requires a detailed understanding of all four components. How and when the species actually arrives in a nonnative region will be determined by those critical long-distance (often intercontinental) dispersal opportunities, and its establishment will depend on initial numbers and demographic processes. How and where it spreads across the new distributional area will depend on smaller-scale dispersal phenomena. Nevertheless, for several reasons, it can be argued that the geographic component of the invasion process often ends up being key.

First, in many cases, colonization opportunities and subsequent establishment of populations are so frequent as to constitute a "rain" of potential colonists. For example, invasive species that take advantage of ballast water as a long-distance movement vector may see hundreds of opportunities for intercontinental colonization, and in such enormous numbers that the demographic considerations may be immaterial (Carlton 1996). Even in more controlled situations, such as the arrival of the Asian longhorned beetle in North America, the number of colonization opportunities is large compared with those that actually lead to invasions (Peterson and Vieglais 2001; NAS 2002). In such situations, and although considerable variance exists in outcomes (Williamson and Fitter 1996), the determining factor stops being the opportunity for colonization and key steps shift to later in the process.

Similarly, the process of spread across the new landscape may be rapid and inexorable. The usual wisdom is that once a nonnative species is established and begins to spread, eradication becomes impossible, and only control remains as an option (Sindel and Michael 1992; Hastings 1996; Perrings et al. 2002). This process of spread, nevertheless, appears to be constrained spatially by the ecological niche of the species. In this sense, whereas the velocity of spread can be so rapid or unstoppable as to make modeling of contagion immaterial, the spatial pattern of the process can still be quite predictable if a good understanding of the ecological niche of the species is available.

In this review, I have presented evidence for the predictability of the geographic dimensions of the process of invasion of a nonnative region. As such, this high predictability constitutes strong evidence for the ecological niche as a stable constraint on the geographic potential of species. Surprisingly, the community context-and concomitant interspecific interactions-in which a species is placed appears to have relatively little influence on geographic dimensions of invasive potential, at least at coarse scales of resolution. This result stands in contrast to recent experimental evidence (Davis et al. 1998) and theoretical ideas (NAS 2002) interpreted as implicating shifting species interactions as removing most or all predictivity of spatial distributions via ecological niches. The experimental approach, however, was developed under extremely restrictive conditions, and with ecologically very similar species (Drosophila spp.) - in short, these experiments were carried out under exactly the circumstances most likely to show the sought-after effects. Given the growing body of evidence developed and reviewed herein, as well as similar and strong opinions based on extensive empirical evidence (Moyle and Light 1996), such circumstances (interspecific interactions removing predictivity) appear to be much more the exception than the rule (NAS 2002).

More generally, the potential contributions from the field of "climate matching" or ecological niche modeling of the geographic potential of species' invasions have been underappreciated (Kareiva 1996; NAS 2002). Although this approach does not provide precise predictions of which species will arrive and invade when and where, it does indeed provide ample and tested predictive ability regarding one important component of the invasion process. Viewed in this sense, this technique has an enormous potential contribution to the field of invasive species biology.

\section{ACKNOWLEDGMENTS}

I thank many colleagues for their incisive thinking and careful research that has made many of the advances of ecological niche modeling possible, in particular Robert P Anderson, Enrique Martínez-Meyer, Ricardo Scachetti-Pereira, Jorge Soberón, David R B Stockwell, and David A Vieglais. James Andreasen has been a 
strong motivating force for further application of these methodologies to additional test cases. Other colleagues and students have contributed important steps forward, including William Hargrove, Miguel
Ortega-Huerta, Daniel A Kluza, Monica Papes, and many others. This work was supported by grants from the U.S. Environmental Protection Agency and the National Science Foundation.

\section{REFERENCES}

Anderson R P, Gómez-Laverde M, Peterson A T. 2002. Geographical distributions of spiny pocket mice in South America: insights from predictive models. Global Ecology and Biogeography 11:131-141.

Anderson R P, Lew D, Peterson A T. 2003. Evaluating predictive models of species' distributions: criteria for selecting optimal models. Ecological Modelling 162:211-232.

Austin M P, Nicholls A O, Margules C R. 1990. Measurement of the realized qualitative niche: environmental niches of five Eucalyptus species. Ecological Monographs 60:161-177.

Breininger D R. 1999. Florida scrub-jay demography and dispersal in a fragmented landscape. Auk 116:520-527.

Brown J S, Pavlovic N B. 1992. Evolution in heterogeneous environments: effects of migration on habitat specialization. Evolutionary Ecology 6:360382.

Burkey T V. 1995. Extinction rates in archipelagoes: implications for populations in fragmented habitats. Conservation Biology 9:527-541.

Carlton J T. 1996. Pattern, process, and prediction in marine invasion ecology. Biological Conservation 78:97-106.

Carpenter G, Gillison A N, Winter J. 1993. DOMAIN: a flexible modeling procedure for mapping potential distributions of plants and animals. Biodiversity and Conservation 2:667-680.

Chapin F S, III, Zavaleta E S, Eviner V T, Naylor R L, Vitousek P M, Reynolds H L, Hooper D U, Lavorel S, Sala O E, Hobbie S E, Mack M C, Diaz S. 2000. Consequences of changing biodiversity. Nature 405:234-242.

Davis A J, Jenkinson L S, Lawton J H, Shorrocks B, Wood S. 1998. Making mistakes when predicting shifts in species range in response to global warming. Nature 391:783-786.

Elton C. 1927. Animal Ecology. London: Sidgwich \& Jackson.

Enserink M. 1999. Biological invaders sweep in. Science 285:1834-1836.

Etterson J R, Shaw R G. 2001. Constraint to adaptive evolution in response to global warming. Science 294:151-154

Feria T P, Peterson A T. 2002. Prediction of bird community composition based on point-occurrence data and inferential algorithms: a valuable tool in biodiversity assessments. Diversity and Distributions 8:49-56.
Fielding A H, Bell J F. 1997. A review of methods for the assessment of prediction errors in conservation presence/absence models. Environmental Conservation 24:38-49.

Grinnell J. 1917. Field tests of theories concerning distributional control. American Naturalist 51:115-128.

Grinnell J. 1924. Geography and evolution. Ecology $5: 225-229$

Hargrove W W, Gardner R H, Turner M G, Romme W H, Despain D G. 2000. Simulating fire patterns in heterogeneous landscapes. Ecological Modelling 135:243-263.

Hastings A. 1996. Models of spatial spread: is the theory complete? Ecology 77:1675-1679.

Higgins S I, Richardson D M, Cowling R M, TrinderSmith T H. 1999. Predicting the landscape-scale distribution of alien plants and their threat to plant diversity. Conservation Biology 13:303-313.

Hobbs R J, Humphries S E. 1995. An integrated approach to the ecology and management of plant invasions. Conservation Biology 9:761-770.

Hoffmann M H. 2001. The distribution of Senecio vulgaris: capacity of climatic range models for predicting adventitious ranges. Flora 196:395-403.

Holt R D. 1996a. Adaptive evolution in source-sink environments: direct and indirect effects of density-dependence on niche evolution. Oikos 75:182192.

Holt R D. 1996b. Demographic constraints in evolution: towards unifying the evolutionary theories of senescence and niche conservatism. Evolutionary Ecology 10:1-11.

Holt R D, Gaines M S. 1992. Analysis of adaptation in heterogeneous landscapes: implications for the evolution of fundamental niches. Evolutionary Ecology 6:433-447.

Holt R D, Gomulkiewicz R. 1996. The evolution of species' niches: population dynamic perspectives. Pages 25-50 in Case Studies in Mathematical Modeling: Ecology, Physiology, and Cell Biology, edited by $\mathrm{H}$ G Othmer et al. Saddle River (NJ): Prentice Hall.

Honig M A, Cowling R M, Richardson D M. 1992. The invasive potential of Australian banksias in SouthAfrican fynbos-a comparison of the reproductive potential of Banksia ericifolia and Leucadendron laureolum. Australian Journal of Ecology 17:305-314.

Huntley B, Bartlein P J, Prentice I C. 1989. Climatic control of the distribution and abundance of beech (Fagus L.) in Europe and North America. Journal of Biogeography 16:551-560. 
Hutchinson G E. 1957. Concluding remarks. Pages 415-427 in Population Studies: Animal Ecology and Demography. Cold Spring Harbor Symposia on Quantitative Biology, Volume 22. Cold Spring Harbor (NY): Cold Spring Harbor Laboratory Press.

Inouye D W, Barr B, Armitage K B, Inouye B D. 2000. Climate change is affecting altitudinal migrants and hibernating species. Proceedings of the National Academy of Sciences 97:1630-1633.

Kambhampati S, Clark J W, Brock B L. 2002. Evolution of host- and habitat association in a cockroach, Cryptocercus. Biological Journal of the Linnean Society 75:163-172.

Kareiva P. 1996. Developing a predictive ecology for non-indigenous species and ecological invasions. Ecology 77:1651-1652.

Karl T R, Knight R W, Easterling D R, Quayle R G. 1996. Indices of climate change for the United States. Bulletin of the American Meteorological Society 77:279-292.

Kawecki T J. 1995. Demography of source-sink populations and the evolution of ecological niches. Evolutionary Ecology 9:38-44.

Kawecki T J, Stearns S C. 1993. The evolution of life histories in spatially heterogeneous environments: optimal reaction norms revisited. Evolutionary Ecology 7:155-174.

Kovats R S, Campbell-Lendrum D H, McMichael A J, Woodward A, Cox J St. H. 2001. Early effects of climate change: do they include changes in vectorborne disease? Philosophical Transactions of the Royal Society of London B 356:1057-1068.

Langeland K A. 1996. Hydrilla verticillata (L.F.) Royle (Hydrocharitaceae), "The perfect aquatic weed". Castanea 61:293-304.

Lonsdale W M. 1994. Inviting trouble: introduced pasture species in northern Australia. Australian Journal of Ecology 19:345-354.

MacArthur R H. 1972. Geographical Ecology: Patterns in the Distribution of Species. New York: Harper \& Row.

Magnuson J. 2000. 150-year global ice record reveals major warming trend. Inter-American Institute of Global Change Research Newsletter 24:22-25.

Malanson G P, Westman W E, Yan Y-L. 1992. Realized versus fundamental niche functions in a model of chaparral response to climatic change. Ecological Modelling 64:261-277.

Manel S, Dias J M, Buckton S T, Ormerod S J. 1999. Alternative methods for predicting species distribution: an illustration with Himalayan river birds. Journal of Applied Ecology 36:734-747.

Martin T E. 2001. Abiotic vs. biotic influences on habitat selection of coexisting species: climate change impacts? Ecology 82:175-188.

Martin W K. 1996. The current and potential distribution of the common myna Acridotheres tristis in Australia. Ети 96:166-173.
Martínez-Meyer E. 2002. Evolutionary trends in ecological niches of species [PhD dissertation]. Lawrence (KS): University of Kansas.

Moyle P B, Light T. 1996. Fish invasions in California: do abiotic factors determine success? Ecology 77:1666-1670.

[NAS] National Research Council: Committee on the Scientific Basis for Predicting the Invasive Potential of Nonindigenous Plants and Plant Pests in the United States. 2002. Predicting Invasions of Nonindigenous Plants and Plant Pests. Washington (DC): National Academy of Sciences.

Nix H A. 1986. A biogeographic analysis of Australian elapid snakes. Pages 4-15 in Snakes: Atlas of Elapid Snakes of Australia, edited by R Longmore. Canberra (Australia): Australian Government Publishing Service.

O'Brien K, Liverman D. 1996. Climate change and variability in Mexico. Pages 55-70 in Climate Variability, Climate Change and Social Vulnerability in the Semi-arid Tropics, edited by J C Ribot et al. Cambridge: Cambridge University Press.

Panetta F D, Dodd J. 1987. Bioclimatic prediction of the potential distribution of skeleton weed Chondrilla juncea L. in Western Australia. Journal of the Australian Institute of Agricultural Science 53:11-16.

Papes M, Peterson A T. 2003. Predictions of the geographic course of the invasion of Ageratina adenophora in China. Journal of Wuhan Botanical Research 21:137-142.

Parmesan C. 1996. Climate and species' range. Nature 382:765-766.

Parmesan C, Ryrholm N, Stefanescu C, Hill J K, Thomas C D, Descimon H, Huntley B, Kaila L, Kullberg J, Tammaru T, Tennent W J, Thomas J A, Warren M. 1999. Poleward shifts in geographical ranges of butterfly species associated with regional warming. Nature 399:579-583.

Perrings C, Williamson M, Barbier E B, Delfino D, Dalmazzone S, Shogren J, Simmons P, Watkinson A. 2002. Biological invasion risks and the public good: an economic perspective. Conservation Ecology Online 6.

Perrins J, Williamson M, Fitter A. 1992. Do annual weeds have predictable characters? Acta Oecologica 13:517-533.

Peterson A T. 2001. Predicting species' geographic distributions based on ecological niche modeling. Condor 103:599-605.

Peterson A T, Ball L G, Cohoon K C. 2002a. Predicting distributions of Mexican birds using ecological niche modelling methods. Ibis Online 144:27-32.

Peterson A T, Cohoon K P. 1999. Sensitivity of distributional prediction algorithms to geographic data completeness. Ecological Modelling 117:159-164.

Peterson A T, Ortega-Huerta M A, Bartley J, SánchezCordero V, Soberón J, Buddemeier R H, Stockwell 
D R B. 2002b. Future projections for Mexican faunas under global climate change scenarios. Nature 416:626-629.

Peterson A T, Papes M, Kluza D A. 2003. Predicting the potential invasive distributions of four alien plant species in North America. Weed Science. In Press.

Peterson A T, Robins C R. 2003. When endangered meets invasive: ecological niche modeling predicts double trouble for spotted owls, Strix occidentalis. Conservation Biology 17:1161-1165.

Peterson A T, Sánchez-Cordero V, Soberón J, Bartley J, Buddemeier R W, Navarro-Sigüenza A G. 2001. Effects of global climate change on geographic distributions of Mexican Cracidae. Ecological Modelling 144:21-30.

Peterson A T, Soberón J, Sánchez-Cordero V. 1999. Conservatism of ecological niches in evolutionary time. Science 285:1265-1267.

Peterson A T, Stockwell D R B, Kluza D A. 2002c. Distributional prediction based on ecological niche modeling of primary occurrence data. Pages 617623 in Predicting Species Occurrences: Issues of Accuracy and Scale, edited by J M Scott et al. Washington (DC): Island Press.

Peterson A T, Vieglais D A. 2001. Predicting species invasions using ecological niche modeling: new approaches from bioinformatics attack a pressing problem. BioScience 51:363-371.

Podger F D, Mummery D C, Palzer C R, Brown M J. 1990. Bioclimatic analysis of the distribution of damage to native plants in Tasmania by Phytophthora cinnamomi. Australian Journal of Ecology 15:281-290

Reichard S H, Hamilton C W. 1997. Predicting invasions of woody plants introduced into North America. Conservation Biology 11:193-203.

Rejmánek M, Richardson D M. 1996. What attributes make some plant species more invasive? Ecology 77:1655-1661.

Ricciardi A, Rasmussen J B. 1998. Predicting the identity and impact of future biological invaders: a priority for aquatic resource management. Canadian Journal of Fisheries and Aquatic Science 55:1759-1765.

Richardson D M, McMahon J P. 1992. A bioclimatic analysis of Eucalyptus nitens to identify potential planting regions in Southern Africa. South African Journal of Science 88:380-387.

Ricklefs R E, Latham R E. 1992. Intercontinental correlation of geographical ranges suggests stasis in ecological traits of relict genera of temperate perennial herbs. American Naturalist 139:13051321.

Root K V. 1998. Evaluating the effects of habitat quality, connectivity, and catastrophes on a threatened species. Ecological Applications 8:854-865.
Scott J K, Panetta F D. 1993. Predicting the Australian weed status of southern African plants. Journal of Biogeography 20:87-93.

Sindel B M, Michael P W. 1992. Spread and potential distribution of Senecio madagascariensis pior (fireweed) in Australia. Australian Journal of Ecology $17: 21-26$.

Skov F. 2000. Potential plant distribution mapping based on climatic similarity. Taxon 49:503-515.

Stockwell D R B. 1999. Genetic algorithms II. Pages 123-144 in Machine Learning Methods for Ecological Applications, edited by A H Fielding. Boston: Kluwer Academic Publishers.

Stockwell D R B, Noble I R. 1992. Induction of sets of rules from animal distribution data: a robust and informative method of analysis. Mathematics and Computers in Simulation 33:385-390.

Stockwell D R B, Peters D P. 1999. The GARP modelling system: problems and solutions to automated spatial prediction. International Journal of Geographic Information Science 13:143-158.

Stockwell D R B, Peterson A T. 2002a. Controlling bias in biodiversity data. Pages 537-546 in Predicting Species Occurrences: Issues of Accuracy and Scale, edited by J M Scott et al. Washington (DC): Island Press.

Stockwell D R B, Peterson A T. 2002b. Effects of sample size on accuracy of species distribution models. Ecological Modelling 148:1-13.

Sutherst R W, Maywald G F, Yonow T, Stevens P M. 1999. CLIMEX User Guide-Predicting the Effects of Climate on Plants and Animals. Victoria (Australia): CSIRO Publishing.

Thorp J R, Lynch R. 2000. The Determination of Weeds of National Significance. Launceston (Australia): National Weeds Strategy Executive Committee.

Visser M E, van Noordwijk A J, Tinbergen J M, Lessells C M. 1998. Warmer springs lead to mistimed reproduction in great tits (Parus major). Proceedings of the Royal Society B 265:1867-1870.

Walther G-R, Post E, Convey P, Menzel A, Parmesan C, Beebee T J C, Fromentin J-M, Hoegh-Guldberg O, Bairlein F. 2002. Ecological responses to recent climate change. Nature 416:389-395.

Warwick S I, Thompson B K, Black L D. 1984. Population variation in Sorghum halepense, Johnson grass, at the northern limits of its range. Canadian Journal of Botany 62:1781-1790.

Welk E, Schubert K, Hoffmann M H. 2002. Present and potential distribution of invasive garlic mustard (Alliaria petiolata) in North America. Diversity and Distributions 8:219-233.

Williamson M. 1996. Biological Invasions. London: Chapman \& Hall.

Williamson M. 1999. Invasions. Ecography 22:5-12.

Williamson M, Fitter A. 1996. The varying success of invaders. Ecology 77:1661-1666. 